\title{
CREATING PEDAGOGY TO INTEGRATE SUSTAINABILITY AND THE ARTS
}

NANCY BERTAUX

(corresponding author)

Economics \& Sustainability

Department of Economics

Xavier University

Cincinnati, Ohio, U.S.A.

bertaux@xavier.edu

KALEEL SKEIRIK

Department of Music

Xavier University

Cincinnati, Ohio, U.S.A.

skeirik@xavier.edu

ABSTRACT. The creation of a sustainable world urgently requires managers of organizations to consider large-scale changes in the practices and policies of social and economic institutions. Compelling scientific and economic information on the environment, while the basis of much dialogue in higher education and in the public sphere, has failed to motivate adequate progress to date. In this article, therefore, we present an original theoretical model for a pedagogy that brings together the arts and sustainability. We postulate that motivation or "heart" to initiate such actions for the environment and persist in the face of societal and institutional inertia can come from the arts, particularly given their unique and time-proven ability to move the human heart in authentic ways. A sustainability pedagogy that utilizes the arts can be incorporated moreover into any discipline at any level of education. This 
pedagogy reaches students not only intellectually but empathetically as well, thereby increasing the depth and effectiveness of learning. Indeed, emphasizing the content characteristics of complexity, modernity, and equity/ justice as well as incorporating student reflection/discernment, experiential learning, and community engagement will further enhance an arts/ sustainability pedagogy. In this light, we briefly examine some preliminary courses integrating the arts and sustainability in four different disciplines, including business. We find these examples indicate that the pedagogy suggested by this theory is a promising avenue to pursue. Finally, we provide some specific suggestions for instructors. New pedagogy that integrates the arts with sustainability can thus contribute significantly to the education of future and current managers, those who are essential agents in effecting needed change.

KEYWORDS: arts and sustainability pedagogy; complexity and sustainability; discernment; modernity; experiential learning; arts and sustainability in higher education

\section{INTRODUCTION AND BACKGROUND}

There is widespread scientific consensus on the need for urgent, large-scale changes in the practices and policies of social and economic institutions to achieve a sustainable world. This reality has been eloquently addressed by Pope Francis in his encyclical Laudato Sí' (Francis, 2015). There is, furthermore, growing recognition in the business and economics community that proceeding with changes aimed at planetary sustainability will be necessary and can be good in the long-term for forward-thinking businesses and sustainable economic development (Whelan \& Fink, 2016; Moran, 2017; Eccles, Ioannou, \& Serafeim, 2012; Peil \& van Staveren, 2009; Sachs, 2015). This is already requiring organizational managers to make changes-dramatic ones in some cases-in a variety of contexts (Soyka, 2012; Dunphy, Griffiths, \& Benn, 2014). The pace in which needed changes are actually achieved, however, has been disturbingly slow given the seriousness of the challenges faced (IPCC, 2014).

The arts as a whole (popular and serious) are vibrant and alive, exerting strong influence on culture, society, and, indeed, on the economy (Heilbrun \& Gray, 2001). The National Endowment for the Arts recently found that the arts sector represents $4.3 \%$ percent of the U.S. gross domestic product, exceeding the construction sector; that 4.7 million are employed in producing arts and cultural goods, receiving 
$\$ 300$ billion in compensation; and that spending on the arts sector creates 62 additional jobs for every 100 new arts jobs (NEA, 2015). The arts and music, furthermore, are highly and passionately significant for students at all levels. Despite this, however, the role of the arts is too often overlooked in pedagogical design.

In light of this, we present in this article an original theoretical construct for a pedagogy that harnesses the arts and sustainability. We postulate that the motivation or "heart" needed by managers and citizens to meet our enormous sustainability challenges, as well as the persistence to overcome societal and institutional inertia, can come from the arts' unique, time-proven ability to move the human heart in authentic ways. The arts can deliver the same general truth and beauty that a scientific paper on sustainability, an economic cost-benefit study, or a business plan does, using messages carried not only via the intellect but also through the spirit, emotions, and their physicality as expressed through sound, vision, and movement.

The theory presented in this article addresses the key roles of complexity (Bertaux \& Skeirik, 2018), modernity (Bertaux, Skeirik, \& Yi, 2015), and equity/justice (Francis, 2015) in designing an effective arts/sustainability pedagogy for any educational context. We argue that such a pedagogy should, whenever possible, utilize greater degrees of artistic sophistication to address the high level of complexity inherent in sustainability, engage today's art for today's sustainability challenges, and incorporate a focus on equity and justice in recognition of the disproportionate impact of environmental concerns on those at the bottom of the pyramid.

Brief, illustrative examples of arts/sustainability pedagogy in the higher education context are given in the final section of the article. University students now expect and demand that their education be conducted with an understanding of how sustainability issues impact their disciplines (Emanuel \& Adams, 2011; Dobson, Quilley, \& Young, 2010). Thus, more than a third of deans of the leading business schools in the world as ranked by the Financial Times report having requirements for sustainability-related curricula in their MBA programs (Christensen \& Worzala, 2010). Commitments to on-campus sustainability practices can also contribute to reinforcing pro-sustainability student behaviors (Durr, Bilecki, \& Li, 2017) — nearly 400 colleges and universities have approved plans for the reduction of carbon emissions, over 100 have comprehensive climate action plans, and many specify carbon neutral/net zero goals for the next one or two decades (Burger, 2018; Second Nature, n.d.; Xavier University, n.d.b). Jesuit universities in the Asia-Pacific region agreed to significant climate action policies and goals (JAPC, 2015). In 2015, 
nearly 200 leading administrators from a wider group of Roman Catholic higher education institutions across the globe (including many Jesuit institutions) signed a statement entitled "In Response to Laudato Sí': On Care for Our Common Home" that committed their institutions to integrate "care for the planet, integral human development, and concern for the poor" in their infrastructures, curricula, research, and community outreach (Ignatian Solidarity Network, n.d.). In this vein, new curricula have emerged in higher education that have placed sustainability issues front and center in diverse areas of study, including business, economics, and many others (Berry, 2011; Rheinlander \& Kramer, 2003; Hill \& Wang, 2018; Xavier University, n.d.a; Chia, 1996).

We have observed, however, both in our own university and in conversations with colleagues at other institutions, that the role of art in sustainability programs and courses is typically minimal or non-existent except for courses taught in arts departments (Kagan \& Kirchberg, 2008). Furthermore, the arts components typically found in the common or core curricula of liberal arts institutions are not environmentally-focused (Harvard University, n.d.; Ohio State University, 2015). This article thus argues that those teaching across all levels, from the earliest ages to adult, should incorporate content that integrates the arts and sustainability into a wide array of courses and contexts. We propose guidelines in the conclusion for those wishing to experiment with the power of the arts in their courses to motivate true change in sustainable practices and policies.

\section{ART AND SUSTAINABILITY}

Objective information is vital to society yet conveying that information to the community often fails at the very first step of public engagement, resulting in a kinetic engagement failure, a disconnect. Accounting systems for sustainable development, for instance, are challenged by "conceptual misconceptions" when constructing sustainable cost calculations (Bebbington \& Gray, 2001). Such misapprehensions are often based upon the failure to understand and incorporate relevant interrelationships and/or cultural and social values. In communicating sustainability, personal commitment and public engagement are key initial components of the messaging solution (Shields, Solar, \& Martin, 2002; Hickman \& Sinha, 2018). The arts in this regard make up a highly effective tool for communicating the sustainability imperative as they generate aesthetic values that contrast with information communicated through the mind alone. 
Understanding the intersection of policy, science, and the public's values and objectives is essential, therefore, for conveying sustainability information and its use in public policy. The arts can be a key component in addressing this intersection (Curtis, 2017; IPCC, 2014) for they lead us to reconsider our thinking about the world first by subjectively reframing content, thereby bypassing any possible "inherited" initial objections and allowing us the opportunity to engage empathetically with the idea before we process the information found therein. Indeed, for science to be utilized effectively, it must be contextualized in terms of social goals and values and presented so that the audience finds meaning in the information. We have argued in previously published work (Bertaux \& Skeirik, 2018) that reaching the threshold of public motivation and involvement in sustainability issues requires more than accurate environmental and human data, intelligently designed sustainable systems, or popular media/political reporting about our challenged relationship with our planet. Art empathetically communicates messages regarding social values and equity through a unique engagement of both the senses and the heart, and is therefore able to evoke understanding, feelings, and commitments directly to personal and social actions. When engaged through the arts (literature, performing/visual arts, or a combination of these), the hearts of individuals spark personal and public engagement in sustainability issues. In this regard, the arts have a competitive advantage over data, analysis, design, and application when it comes to motivating and educating people about the critical importance of creative and sustainable decision-making and action.

The arts can thus function as a type of language (and often a universal language indeed) which, when combined with a sense of place, becomes a strong communicator (Mackinnon-Day, 2016). As part of our media world, they can create any number of new "resonant frames" to engage the public on issues such as climate change (Moser, 2014). Indeed, truly sustainable solutions to the many ecological and social challenges we face require increased levels of citizen participation and a re-making of our collective consciousness which is currently in conflict with today's realities (Sterling, 2014). As such, these new frames of reference that are founded in aesthetic and experiential learning, which the arts can provide, will help shift the currently info-centric tendency of public engagement on sustainability (Bendor, Maggs, Peake, Robinson, \& Williams, 2017).

We have also argued that it is essential for artists and the public who engage in the arts and sustainability issues of our time to move that engagement in the direction of higher levels of artistic complexity. Sustainability problems and policies are incredibly complex as demonstrated by the physical, biological, economic, and human sets of 
interrelationships that impact sustainable systems and solutions. Arts that incorporate degrees of complexity, when given breadth and freedom, thus become both an aesthetic and pedagogical tool to assist society in focusing and advancing sustainable solutions for the Earth (Bertaux \& Skeirik, 2018; EcoJesuit, 2018). This is especially critical given that we view mass media today, with its "on" switch forever frozen in place, as a type of gravity that draws the public in to serve it a large portion of its intellectual content. To maintain or grow its market, however, the media now is structured to deliver simple content in the fastest way possible (Twitter, Facebook, Internet news, etc.). It is poorly suited in general to manage the delivery of information about critical, complex, and impending ecological and economic failures, such as the relationship between climate change and migration/immigration or the social and ecological impact of a food supply that relies heavily on fossil fuels, irrigation, and techniques that undermine topsoil quantity and quality. Due to the nature, therefore, of market-based components of media messaging systems, the media organization is forced to avoid complexity and deliver only highly simplified dimensions of more complex issues, leading to an audience disconnect or, at best, a conveyance of effective misinformation that is incomplete and devoid of its complex context. Developing a way of communicating the complexity of a sustainability issue to the heart and engaging the values of the individual and the public is a proper role, then, for the arts.

Lastly, we have maintained that the flourishing of art that reflects our current culture is an imperative as opposed to an excessive focus on historical art expressed by what is considered "canonical" in the various fields within art (Bertaux et al., 2015). Art is for everyone, from the novice to the dedicated artist, and people only need to be exposed to art for artistic experiences to commence. Indeed, the world is adrift in a sea of readily available, simple, and democratic arts, everything from garage band music to commercial art symbols used to advertise products. The electrification of our world, moreover, has brought these simple arts to more and more of us, everywhere, and all the time. We thus have an active delivery system, yet one that not yet carrying the cargo that it could-namely, contemporary, complex, and artistic messages required for true progress on sustainability issues.

To sum up, we need art because art subjectively communicates vital messages about society by way of the heart and can thus impact cultural values and equity/justice through its uniquely high degree of public engagement. We need complexity in art today because artistic impact on sustainability will be most transformative when combined with a consistent nudge toward increasing levels of complexity in our art and our understanding. We need greater emphasis on a fertile environment 
for the growth of contemporary art that is based on current realities and social challenges, including the many ecological and social crises we face today.

\section{SUSTAINABILITY PEDAGOGY AND THE ARTS}

There is convincing scholarship on the general effectiveness of the arts for enhancing pedagogy across many contexts. Authors have documented that the arts can effectively influence the "aesthetic, epistemological, ethical, ontological, and political aspects of curriculum across a wide array of curricula" (Willis \& Schubert, 1991). At the high school level, for example, vibrant discussion on cross-disciplinary approaches is bringing the arts into each discipline (Boston, 1996). Incorporating art into pedagogies is effective at changing pre-conceptions about our world because the artistic process and content, as discussed in the previous section, help students creatively re-frame the world (Gunn, 2016). Business schools, in particular, have used this creative re-framing aspect of the arts in management and entrepreneurship programsby experiencing and studying the arts (drama, drama literature, and symphonic conducting), management techniques are enriched and instruction is made more effective (Mockler, 2002). The study of arts-based processes, moreover, develops unique skills for individual organization managers when these are re-applied to management (Taylor \& Ladkin, 2009). Still others demonstrate that arts-based learning is a key foundation in general for business and management education (Nissley, 2010). Indeed, integrating the arts into business school curricula awakens the "entrepreneurial imagination" and initiates new thought processes for the resolution of stubborn barriers to business solutions (Wankel \& DeFillippi, 2002).

With respect to sustainability pedagogy specifically, scholars have demonstrated the usefulness of the arts at all levels of education. Preschool curricula that study seemingly unrelated concepts about the natural world through art yield unique educational benefits in terms of awareness about local environment and culture (Ward, 2013). Environmentally-based storytelling, drama, and visual arts in an elementary school in Botswana resulted in better communication and a more egalitarian, locally-connected educational experience (Silo \& Khudu-Petersen, 2016). Despite this, however, studies of sustainability pedagogy often overlook the potential role of the arts in uniquely engaging students (Cullingford \& Blewitt, 2013; Caniglia et al., 2017).

Nevertheless, a wide range of organizations in sectors from defense to education recognize the importance of pedagogy that integrates the 
arts and sustainability (Allen-Gil, Stelljes, \& Borysova, 2009; Medrick, 2013). This pedagogy simply begins with exposure to both areas inside the framework of a single course, with such exposure possibly occurring when faculty present or assign actual artistic works (as opposed to secondary sources that merely describe them) or, in the case of an arts program, sustainability content. Students can also gain exposure by having one or more of their peers bring in or present to the class artistic works related to course content within their discipline, or sustainability content in the case of an arts course. Finally, exposure can also be had by having one or more students create their own artistic work which could then be presented to the class or, in the case of an arts course, sustainability content which would be included in one or more of the student works created. Note thus that the amount of exposure to art in any non-art course, or to sustainability in any non-sustainability course, is quite flexible. It may be as minimal as is necessary or desired, such as one student presentation or one part of a lecture in a course, or it may be the primary focus of the entire program. Faculty are invited to begin small, with a single example or component, and build appropriately as confidence and experience are gained.

In accordance, therefore, with the theory presented above, the greatest desired impact from integrating the arts and sustainability in a course or program occurs when the curriculum pushes the envelope in three specific directions: artistic complexity, contemporary art, and content related to equity. Artistic complexity should first be encouraged, especially when this complexity is related to intersections between earth's systems and our own human systems and institutions. In terms of pedagogy, it is not sufficient to limit sustainability instruction to the essential logical information within a particular discipline because content exposure in and of itself is weak when it comes to motivation, values, and engagement on complex modern issues. Indeed, the pedagogy of values and engagement is not a typical part of a standard secondary text. Consider a simple example, such as an economics textbook that has a chapter or section discussing pollution as an economic externality (Colander, 2016) which could lead to an intellectual reaction on the part of the student. An empathetic and potentially deeper impact could occur if artistic content were included and presented in the course, such as paintings of a landscape before and after pollution (Hattam, 2010).

Students ignite their creative energy to solve sustainability problems when artistic works related to their discipline are integrated with the sustainability challenge within the curriculum. A broader range of more creative solutions occurs in this newly expanded curriculum because students do differ in their individual empathetic reactions to modern complex problems when they are stimulated by an artwork. For a more 
involved example, compare a rap addressed to future generations on the diminishing number of forests (Prince Ea, 2015) to a textbook narrative on sustainable forestry in an ecological economics textbook. Each offers important but different information about sustainability and forests. The drama, intensity, and exaggeration in Prince Ea's rap music video pulses and paints into the heart of the student a shocking future made up exclusively of artificial trees! Clearly, Prince Ea intentionally exceeds the boundaries of a textbook, yet it is this very excess, unreasonable by common standards, that ignites the critical component within the classroom, ensuring the birth of a broader array of creative solutions. Each student's personal interpretation of Prince Ea's video also forges ideas of ownership and engagement, and the layers of meaning found in this complex work parallel the deep complexity of the topic as Daly and Farley (2011) outline in their textbook. This stereophonic form of instruction provides the student with a way to own the material as an individual, and sets the class up to work as a team to overcome their differences in values and attitudes. Note that this in turn can assist in removing inappropriate filters of ideas that may pre-exist in students and inhibit learning (Djordjevic \& Cotton, 2011). Our theory thus implies that the higher education classroom considering sustainability should ignite the complexity/value matrix when examining the information, intellectual, and analytical aspects of a sustainability issue.

Some might argue that art-inspired fantasies or imaginings are not part of a rigorous curriculum. We argue otherwise because the solutions to the matrix of sustainability issues on this planet are still in process and yet urgently needed (McKibben, 2010). We no longer have the luxury of time to teach our courses within silos, and so we are suggesting a tool for any discipline that instructs in an area of sustainability, a tool to break out of that discipline's silo while simultaneously leading the student into the complexity of the issues. That tool is to incorporate one or more artistic components, preferably at a high level of complexity, which bring forth creative interpretations and imaginings, motivation and values. Indeed, our challenged culture demands and deserves the maximal number of creative resolutions to its multi-faceted problems, and we argue that the best ones can be furthered in higher education instruction that integrates imaginings arising out of artworks with rigorous academic curricula. It is in this way, when pedagogy integrates the arts and sustainability, that artistic complexity will assist in generating maximum impact.

The second direction to highlight in this pedagogical integration is in emphasizing the inclusion of contemporary artistic works, as is the case with both examples given above. Note that this definition of "contemporary" is flexible as it may vary within artistic disciplines and, indeed, with the sustainability issue to be considered within a 
course (Bertaux et al., 2015). Some issues, for instance, are more recently manifested while others may have been quite long-lasting. Duncan Macmillan's 2011 play "Lungs" (Macmillan, 2011) is an example of a very recent sustainability issue; in it, a couple is deciding whether to bring a child into this world given its deeply troubling environmental challenges and the likely negative impact on that child's future. Evoking a deep sense of place and involvement with nature, Merce Cunningham's dance work "Rainforest" (Cunningham, Tudor, Cage, Leacock, Pennebaker, \& Oppenheim, 1968) is, on the other hand, an example of a work that is 50 years old but still arguably contemporary. Nevertheless, it should be noted that we are not arguing that all artistic content be contemporary as historical works can still be important inspiration. For example, classroom discussion of the long-lasting issue of technology's disruption of nature can be enhanced by presenting JMW Turner's $19^{\text {th }}$ century painting entitled "Rain, Steam and Speed" (Turner, 1844). While not contemporary, this work can be included and treated in the course as still relevant for today.

The third direction suggested for pedagogy consideration, in line with our growing recognition of the mutual dependency between social and environmental sustainability, is that artistic works should significantly represent themes of human development, equity, and justice (Nulkar, 2016; Lauesen, 2016). The field of architecture demonstrates, for example, how sustainability has penetrated deeply into the ways society's everyday spaces are thought out, with designs beginning to consider with a conscience the impact on various members and segments of the public (Blincoe et al., 2009; Christensen \& Worzala, 2010). In the last decade or so, architecture theories as well as practices such as LEED (Leadership in Energy and Environmental Design) standards have reframed the design of space and the organization of cities through the lens of equitable urban development; such is reflected in the NEA (National Endowment for the Arts) grant awards (Harvey, 2010; Dempsey, Bramley, Power, \& Brown, 2011; IHCD, n.d.; Kibert, 2016). Other arts, though, can also serve to explore the relationship between equity and sustainability, including the opera on human trafficking entitled Angel's Bones (Yun, 2011), the instrumental composition on polar ice melting Become Ocean (Adams, 2013), the novel on immigration entitled Miss Ex-Yugoslavia (Stefanovic, 2018), the book of poetry on the importance of place-centered thinking Sustainable Poetry: Four American Ecopoets (Scigaj, 2015), and the film Time of the Wolf (Haneke, 2003) about the end of the world and disaster.

In addition to encouraging the three content-based directions as described above (complexity, modernity, and equity/justice), we want to highlight the potential contributions of experiential learning, community engagement, and reflection/discernment, pedagogical techniques which 
can be utilized separately or in combinations. Experiential learning, which can be problem, project, or place-based, has been shown to deepen student learning and can be used in many courses that integrate the arts and sustainability. Community-engaged (or service) learning can be conceptualized as a type of experiential learning that engages students with an actual community, usually close to the campus or other classroom site, and as a valuable way of exposing students to the realworld complexities of sustainability policies and practices or possibly even the art-sustainability nexus (Holden, Elverum, Nesbit, Robinson, Yen, \& Moore, 2008; Wurdinger \& Carlson, 2010). It should be noted thus that since experiential learning and community engagement will serve to deepen the context of the entire course, these techniques, even if used separately from the arts-sustainability integration component, can still assist in said integration within the course itself.

Finally, we argue that guiding students during a course to reflect and discern deliberately is an inherent contribution to the integration of the arts into sustainability pedagogy. Discernment as a learning process parallels the artistic experience in many ways. The artist intentionally manipulates and skillfully crafts a mirror of society and reflects back their interpreted understanding/vision/impression of that society, however accurate or corrupted it may intentionally be. The observer of the artwork, in this case the student, will not necessarily develop a logical and linear reaction to it; in fact, the ideas students find in an artwork often arise from associations they bring to the work. Each subjective reaction may thus be unique and invite dialogue with classmates and faculty (Skeirik, n.d.). Discernment as such may be seen as a type of reflexive capital or positive feedback loop that uses personal reflection to motivate modification and improvement of human behaviors and policies. In this case, the feedback loop involves student awareness of, and attitudes or beliefs regarding, sustainability challenges and how to address them. Aesthetically-based discernment, therefore, is a potentially important change agent whereby sustainability education can lead to effective actions (Dieleman, 2008).

In the technique of discernment, we encounter what the arts do best-fueling the imagination that reframes current thinking and envisions new futures. The arts activate sensorial and mental ownership of these visions and, yes, even utilize what may at first be confusion or a lack of clarity as we enter into the world of new visualizations. These are prerequisites to learning about sustainability-for example, anyone desiring to imagine a culture that will address a sixth mass extinction on our planet (Kolbert, 2014) will need to deal with the intersections of a new vision, data documenting a difficult current reality, and the understandable confusion that results as students and 
scholars grapple with possible solutions. Invoking the discernment process in the classroom provides a tool for navigating this difficult aesthetic and intellectual terrain.

\section{The Pedagogy of Art and Sustainability}

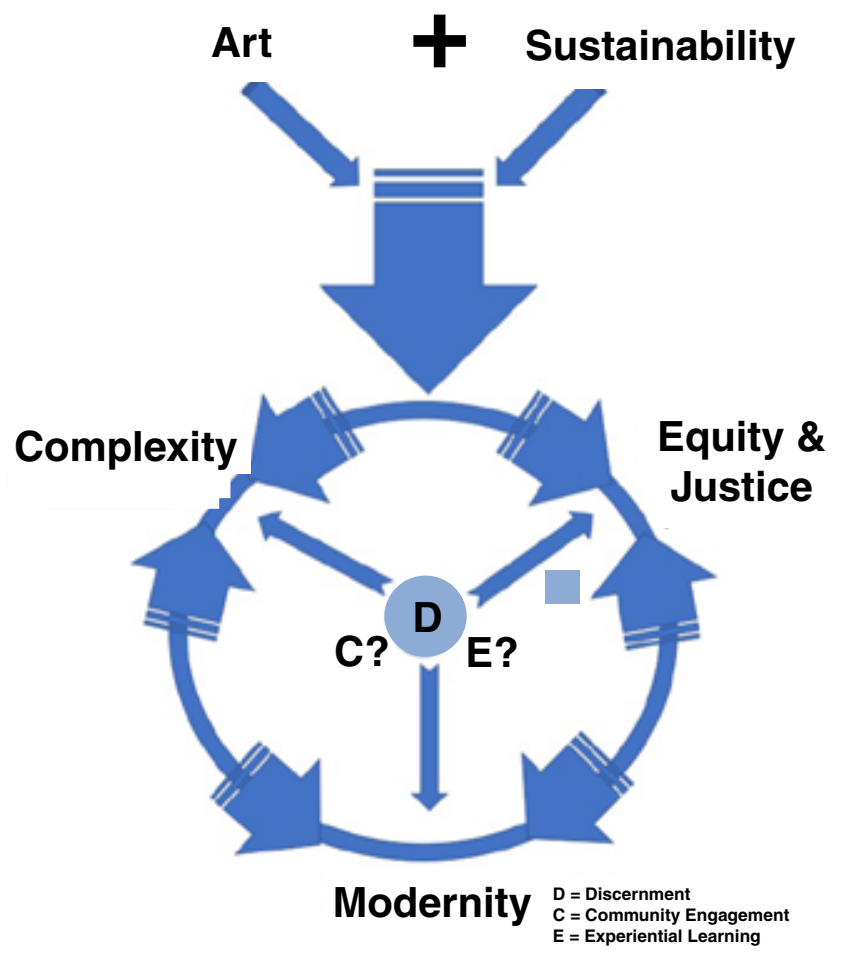

Figure 1: The Pedagogy of Art and Sustainability

Faculty should thus consider these three content characteristicscomplexity, contemporariness, and equity-when designing their course or course components. To make sure students understand these characteristics, the course design should include guidelines for (or conversations with) students to assist them as they bring in, present, create, interpret, and discuss artistic works for the course. Moreover, the pedagogical techniques of experiential learning, community engagement, and discernment will, singly or in combination, make traversing the frontier of the arts and sustainability pedagogy more effective. That integration of the arts in pedagogy inherently incorporates 
extensive opportunity for students' conscious discernment and provides a path through the multiple interpretations that emerge from such an integration is thus of special note. Figure 1 illustrates the relationship between the main content areas to be addressed (art and sustainability), the suggested characteristics or directions to be encouraged in the content (complexity, modernity, and equity/justice), and the techniques that are inherently present (discernment) or possibly present (experiential learning and community engagement).

We note that the pedagogy envisioned here is consistent with several Ignatian concepts, including discernment, community engagement, and concern for equity, and with recent initiatives on an Ignatian pedagogy for sustainability as articulated by the AJCU Ecology Educators (AJCU Ecology Educators, n.d.).

\section{SOME PRELIMINARY EXAMPLES}

This section will present a few illustrative examples of actual course content that integrates the arts and sustainability. Prior to choosing the examples, we reviewed relevant literature and notes from numerous presentations on the topic by authors at scholarly conferences, including feedback and discussions with colleagues on incorporation of the arts into sustainability pedagogy for higher education. Due, however, to the small number of courses following this pedagogy and the difficulties inherent in locating them, examples for this preliminary study were selected from courses the authors had planned and taught as well as from courses taught by colleagues in other disciplines at the same university. The latter were identified by emailing all colleagues who had participated in specific academic sustainability initiatives and following up with those who responded. This process resulted in an initial review of four courses and two intensive off-campus programs from a variety of disciplines (economics, music, history, sustainability, and digital media), all of which integrated art with sustainability content. The courses were located in two different colleges (business and arts and science) at Xavier University in Cincinnati, Ohio, a Jesuit, Roman Catholic university founded in 1831 with a student body of approximately 4,650 undergraduates and 2,150 graduate students. A few courses were selected from the initial group of courses identified to show possibilities across disciplines, type, and level of course. To suggest how the theory presented above could be applied to specific courses, a simple review of relevant course content from these selected courses, i.e., content incorporating the arts into sustainability topics, as well as of any available feedback from faculty and students was conducted. 
The courses selected were as follows:

1. Music, War \& Peace (Music 109)

2. Natural Resource, Ecological \& Environmental Economics (Economics 320)

3. Urban Ecologies, Urban Economies (History 536)

4. Senior Project, Digital Media (Digital Media xxx)

1. A review of Music, War \& Peace (Skeirik, 2014) involved students from all undergraduate majors who were in the artistic field of music. The course, which fulfills a university-wide undergraduate common core requirement for an elective in Ethics/Religion and Society, has for its theme a focus on guiding student discernment regarding the many interpretations and meanings of war and peace. An important interpretation thus explored is the notion of whether humanity is at peace or war with nature. On this point, students analyzed the sustainability content in the recorded and published work of composers and musicians. The professor, who provided both audio and video/audio examples as part of the required material for the course, notably included works that addressed both equity/social and ecological sustainability as well as contemporary, new, and complex works such as Julia Wolfe's 2015 composition Anthracite Fields which uses as inspiration the physical and social history of coal in Pennsylvania. In addition to this, students also brought examples from their own musical listening experiences to class as part of the course content. Here we see a good example of bringing in and analyzing sustainability content in a course that on its face would not seem to be an obvious place for such.

2. Natural Resource, Ecological \& Environmental Economics (Bertaux, 2014), in addition to being a required course for the several interdisciplinary and sustainability-oriented undergraduate academic programs at Xavier University, ${ }^{1}$ is also taken as an elective by many economics majors and minors who may have little or no background in environmental issues. This course also fulfills a university-wide undergraduate common core requirement for an elective in Ethics/ Religion and Society as well as being an elective for the Peace and Justice Studies minor.

Below is a description posted on the course management software system for one of the first assignments in the course. Note that students present these to the class using a sense of "place" from their own lives

${ }^{1}$ These are BA in Economics, Sustainability \& Society; BS in Environmental Science; BA in Land, Farming, and Community; BSBA in Sustainability: Economics \& Management; and the Environmental Studies minor. 
(Figures 2 and 3); the assignment also serves as the way in which students introduce themselves to each other.

"Where I'm From" assignment (for the first week of class): Bring/post an artistic creation to share with the class. This should be something that you have created/altered, and that expresses "Where I Come From." This can be a drawing, video, essay, photograph, piece of music, three dimensional object/sculpture, collage, painting, poem, etc. Presentation time will be no more than 1 minute. It must reflect or express the physical, geographical location that you consider to be "where you are from" (which may or may not be where you are born or where you reside now).

Post an image, link or file with your creation here. If you are bringing a physical item, post a photo of it here.

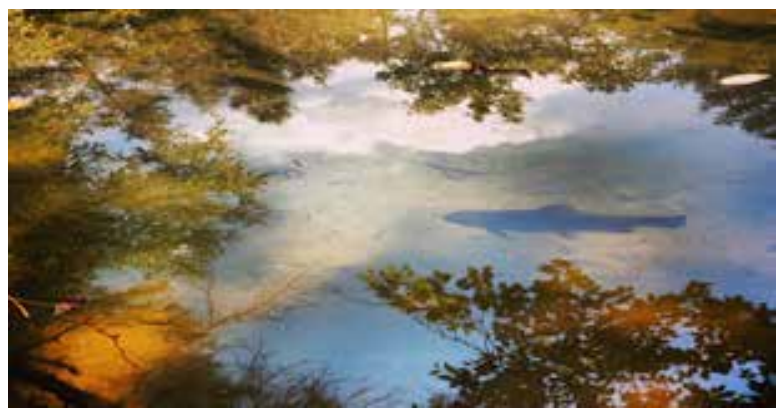

Figure 2: Where I'm From: Pittsburgh (Student output from Natural Resource, Ecological, \& Environmental Economics [Economics 320, Xavier University])

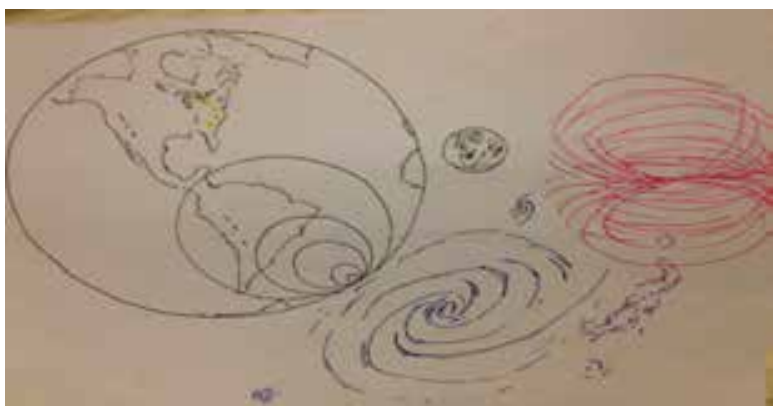

Figure 3: Where I'm From: The Universe (Student output from Natural Resource, Ecological, \& Environmental Economics [Economics 320, Xavier University])

Students return to this concept later in the course by using discernment/reflection to apply course material to their "place"; they have, for example, an assignment where they apply to their given place 
textbook classifications of various types of ecological resources used in economic activity. Students' own reactions and feelings about the present and future of their place are then shared and discussed in class. This course thus provides a good example of bringing and analyzing artistic understandings and interpretations of sustainability content in a discipline that rarely utilizes the arts in any manner at all. It is a good example of encouraging non-artistic majors to create artistic works, allowing them to understand that artistic creation is not only for dedicated "artists" but for all of us, and to harness the power of that understanding to motivate further study of the sustainability content on which the course is based. Indeed, while the students' own artistic creations for the course are not necessarily complex or sophisticated, the course content to which these creations are related is certainly at an intermediate level. Finally, the course also includes community-engaged, experiential, and project-based learning, thereby adding to opportunities for integration and discernment.

3. A required course for the interdisciplinary MA in Urban Sustainability and Resilience at Xavier University, Urban Ecologies, Urban Economies (The Ecological City, 2012) is an example of a graduate-level course wholly dedicated to sustainability content in a field (social and ecological history) that does not typically incorporate artistic work. Indeed, while the use of artistic examples to "set the stage" for trends and events being discussed is not uncommon in fields like history, they are typically brief and not strongly emphasized. In this course, however, a major experiential learning assignment involves students producing videos for a course website about their own visions for the future of the city they currently reside in, namely, Cincinnati, Ohio. They are guided along a number of important avenues of learning: course concepts are applied to a real world vision; students engage with the community and discern key issues as they develop material and perform interviews for their video; a sense of place which they can carry to wherever they locate in the future is encouraged; and, once again, having "non-artist" students produce an artistic work engages the imagination, allowing a deepening of learning for the rest of the course.

4. Senior Project, Digital Media (Xavier University Communication Department, n.d.) is a second example of an artistic course that can be applied to sustainability. In this case, digital media majors choose the topic of their required senior video project without sustainability content being a requirement. The professor's strong interest in sustainability, however, and her own produced works, including an award-winning film on the subject (DeVault, 2013), can serve to encourage students who might have an interest in this content. This is an example of an entire course dedicated to experiential learning through the artistic creation 
of students, along with opportunity for reflection and discernment on the project theme chosen. The course is also an example of relatively complex and sophisticated artistic creation-according to the standards of undergraduate curricula-by virtue of its placement as the final senior product of a major in an artistic discipline. An example viewed by the authors-a student's senior project video on local air pollution-also shows community engagement and development of a sense of place through place visits and interviews.

Preliminary and subjective assessments of the efficacy of arts and sustainability integration in these selected sample courses included review of relevant assignments and available student feedback as well as conversations with professors. Our initial impressions from these assessments suggest that adding an integrated arts and sustainability course component or focus appeared to have enhanced the effectiveness and/or depth of student learning. Each professor answered yes to the question "Is the additional insight and dedication gained worth the time it takes away from other course content?" This is not, however, a conclusion based on a rigorous selection process for courses nor on a systematic assessment of learning in the courses studied. A further caveat is that none of these samples included online or off-campus courses or programs. Finally, courses from only four disciplines were examined. Nevertheless, our initial evaluation does indicate that developing a more rigorous and systematic process of evaluating the effectiveness of integrating arts and sustainability across the curriculum could be a promising avenue for further research. For such research to proceed, ways must be found to identify courses that currently integrate arts and sustainability and a systematic process designed to review and assess the integrated component.

\section{CONCLUSION}

We have developed a theory for an initial pedagogy on art and sustainability that can serve as a foundation structure for sustainabilityrelated courses. This theory, moreover, can be adapted to any educational level despite us having presented only examples from higher education. Indeed, a flexible and innovative pedagogy integrating the arts and sustainability presents a unique opportunity for the classroom due to the wide array of art currently available in our cultures or that students may create as part of a course. It is the unbounded aspect of the arts that provides this pedagogy with the chance to stimulate more creative solutions and thus add significant value. 
We have also explained how and why the integration of art and sustainability in any discipline, especially when pressed into more complex, modern, and equity-focused directions, can result in improved, student-driven solutions to sustainability challenges and thus bring forth deeper student awareness and motivation directed at "healing a broken world" (Álvarez, 2011). The crucial role managers play in organizations gives an added urgency to the incorporation of this pedagogy into the education of future and current leaders.

We summarize below six simple faculty/teacher guidelines for this new pedagogy of the arts and sustainability:

1. Bring art into the classroom even in a small way.

2. Always try to increase the complexity of artistic content and assignments.

3. Always try to include art that is contemporary.

4. Always encourage addressing equity and social sustainability issues.

5. Invoke the discernment process to relate art to course content.

6. Consider including community engagement or other form of experiential learning.

The higher education academy, for its part, should increase support for the efforts listed above through individual institutions and organizations for higher education ( $\mathrm{O}^{\prime}$ Connor \& Gray, 2016). It should increase its efforts to nurture the creation of new artistic works by students, faculty, and the community at large as a contextual form of support for such. This kind of support is important for all levels of teaching institutions, from pre-school to adult.

New pedagogy that integrates the arts with sustainability can contribute significantly to the education of current and future managers for becoming critical agents in re-framing and implementing needed changes. Art is the heart-felt link between culture and life's challenges on Earth, and creative pedagogies that incorporate the arts lead students to understanding first through the heart. To live in and restore synergistic systems on Earth, we need students with a whole body, heart, and mind commitment to conceive, create, implement, and manage innovative new solutions on each sustainability front. By guiding them to learn from art across many more courses, we can unleash the empathetic processes in students to ensure deep engagement within each of our disciplines. Art, in short, adds pulsing heart to sustainability learning. 


\section{REFERENCES}

Adams, L. 2013. Become ocean. Taiga Press/Theodore Front Musical Literature. Available at http://www.pulitzer.org/winners/john-luther-adams (accessed May 30, 2018).

AJCU Ecology Educators. (n.d.). AJCU Ecology Educators. Available at https://www. xavier.edu/jesuitresource/jesuit-a-z/terms-s/ajcu-ecology-educators.

Allen-Gil, S., Stelljes, L., \& Borysova, O. (Eds.). 2009. Addressing global environmental security through innovative educational curricula. NATO Science for Peace and Security Series C: Environmental Security. Dordrecht: Springer. Available at http://search.ebscohost.com/login.aspx?direct=true\&db $=$ ecn\&AN=1041645\&login .asp\&site $=$ ehost-live\&scope=site.

Álvarez, P. (Ed.). 2011. Healing a broken world. Special Report on Ecology. No. 106, 2011/2. Social Justice Secretariat at the General Curia of the Society of Jesus. Available at https://issuu.com/sjssj/docs/healing_a_broken_world (accessed May 31, 2018).

Bebbington, J., \& Gray, R. 2001. An account of sustainability: Failure, success and a reconceptualization. Critical Perspectives on Accounting, 12(5): 557-587. DOI: 10.1006/cpac.2000.0450.

Bendor, R., Maggs, D., Peake, R., Robinson, J., \& Williams, S. 2017. The imaginary worlds of sustainability: Observations from an interactive art installation. Ecology and Society, 22(2). Available at https://www-jstor-org.nocdbproxy.xavier.edu/ stable/26270091?seq=1\#page_scan_tab_contents.

Berry, T. 2011. The great work: Our way into the future. Crown/Archetype.

Bertaux, N. E. 2014. ECON 320. Available at https://bertaux.wordpress.com/econ-320/.

Bertaux, N., \& Skeirik, K. 2018. Toward a theory of the arts and sustainability. Journal of Management for Global Sustainability, 5(2): 53-73.

Bertaux, N., Skeirik, K., \& Yi, D. 2015. Art music and the economy: The modernity index and the Cincinnati Symphony Orchestra, 1895 to 2013. International Journal of Economics and Business Research, 9(4): 376-392.

Blincoe, K., Fuad-Luke, A., Spangenberg, J. H., Thomson, M., Holmgren, D., Jaschke, K., Ainsworth, T., \& Tylka, K. 2009. DEEDS: A teaching and learning resource to help mainstream sustainability into everyday design teaching and professional practice. International Journal of Innovation and Sustainable Development, 4(1): 1-23.

Boston, B. O. 1996. Connections: The arts and the integration of the high school curriculum. New York, NY: College Board Publications. Available at https://eric. ed.gov/?id=ED407317.

Burger, A. 2018. Can biogas CHP help Duke University meet aggressive climate goals? Microgrid Knowledge, 2018. Available at https://microgridknowledge. com/renewable-biogas-duke-university/.

Caniglia, G., Luederitz, C., Groß, M., Muhr, M., John, B., Keeler, L. W., von Wehrden, H., Laubichler, M., Wiek, A., \& Lang, D. 2017. Transnational collaboration for sustainability in higher education: Lessons from a systematic review. Journal of Cleaner Production, 168: 764-779. DOI: 10.1016/j.jclepro.2017.07.256. 
Chia, R. 1996. Teaching paradigm shifting in management education: University business schools and the entrepreneurial imagination. Journal of Management Studies, 33(4): 409-428. DOI: 10.1111/j.1467-6486.1996.tb00162.x.

Christensen, P., \& Worzala, E. 2010. Teaching sustainability: Applying studio pedagogy to develop an alternative post-hurricane housing solution using surplus shipping containers. Journal of Sustainable Real Estate, 2(1): 335-360. Colander, D. C. 2016. Microeconomics. New York, NY: McGraw-Hill Education.

Cullingford, C., \& Blewitt, J. 2013. The sustainability curriculum: The challenge for higher education. Routledge.

Cunningham, M., Tudor, D., Cage, J., Leacock, R., Pennebaker, D. A., \& Oppenheim, D. 1968. Rainforest. Merce Cunningham Dance Company/Pennebaker Hegedus Films.

Curtis, D. (Ed.). 2017. Building sustainability with the arts: Proceedings of the 2nd National EcoArts Australis Conference. Newcastle-upon-Tyne, UK: Cambridge Scholars Publishing.

Daly, H. E., \& Farley, J. C. 2011. Ecological economics: Principles and applications. Washington, DC: Island Press.

Dempsey, N., Bramley, G., Power, S., \& Brown, C. 2011. The social dimension of sustainable development: Defining urban social sustainability. Sustainable Development, 19(5): 289-300. DOI: 10.1002/sd.417.

DeVault, B. 2013. The sanctity of sanctuary: Paul Strauss and the Equinox Farm. The Sanctity of Sanctuary.

Dieleman, H. 2008. Sustainability, art and reflexivity: Why artists and designers may become key change agents in sustainability. In S. Kagan \& V. Kirchberg (Eds.), Sustainability: A new frontier for the arts and cultures: 1-27. Frankfurt am Main: Verlag für Akademische Schriften. Available at https://www.researchgate. net/profile/Hans_Dieleman/publication/277022023_Sustainability_Artists_and_ Reflexivity/links/555fcc1e08ae86c06b6371b9.pdf.

Djordjevic, A., \& Cotton, D. R. E. 2011. Communicating the sustainability message in higher education institutions. International Journal of Sustainability in Higher Education, 12(4): 381-394. DOI: 10.1108/14676371111168296.

Dobson, A., Quilley, S., \& Young, W. 2010. Sustainability as competitive advantage in higher education in the UK. International Journal of Environment and Sustainable Development, 9(4): 330-348.

Dunphy, D., Griffiths, A., \& Benn, S. 2014. Organizational change for corporate sustainability (3rd ed.). Routledge.

Durr, E., Bilecki, J., \& Li, E. 2017. Are beliefs in the importance of pro-environmental behaviors correlated with pro-environmental behaviors at a college campus? Sustainability: The Journal of Record, 10(3): 204-210. DOI: 10.1089/ sus.2017.29105.ed.

Eccles, R. G., Ioannou, I., \& Serafeim, G. 2012. The impact of corporate sustainability on organizational processes and performance. Working Paper No. 17950. National Bureau of Economic Research. Available at https://www.nber.org/ papers/w17950.pdf. DOI: 10.3386/w17950. 
EcoJesuit. 2018. Ecology and Jesuits in communication. Available at http://www. ecojesuit.com/ (accessed Aug. 6, 2018).

Emanuel, R., \& Adams, J. N. 2011. College students' perceptions of campus sustainability. International Journal of Sustainability in Higher Education, 12(1): 79-92. DOI: 10.1108/14676371111098320.

Francis. 2015. Laudato si': On care for our common home. Huntington, IN: Our Sunday Visitor.

Gunn, V. 2016. Prophetic nomadism: An art school sustainability-oriented educational aim? International Journal of Art \& Design Education, 35(3): 316-326.

Haneke, M. 2003. Time of the wolf. Arte France Cinéma / Bavaria Film / Canal+ / Centre National de la Cinématographie (CNC) / Eurimages / France 3 Cinéma / Les Films du Losange / Wega Film.

Harvard University. (n.d.). New college requirements. Available at https://handbook. fas.harvard.edu/book/new-college-requirements (accessed May 25, 2018).

Harvey, D. 2010. Social justice and the city. University of Georgia Press.

Hattam, J. 2010. Famous Chinese artist paints polluted waters. TreeHugger. Available at https://www.treehugger.com/culture/famous-chinese-artist-paints-pollutedwaters.html (accessed May 29, 2018).

Heilbrun, J., \& Gray, C. M. 2001. The economics of art and culture. Cambridge University Press.

Hickman, R., \& Sinha, P. 2018. The Sabar ways of knowing: Sustainable ideas towards educational ecology. International Journal of Art \& Design Education, 71(1): 113-124. DOI: http://dx.doi.org/10.1111/jade.12137.

Hill, L. M., \& Wang, D. 2018. Integrating sustainability learning outcomes into a university curriculum: A case study of institutional dynamics. International Journal of Sustainability in Higher Education, 19(4): 699-720.

Holden, M., Elverum, D., Nesbit, S., Robinson, J., Yen, D., \& Moore, J. 2008. Learning teaching in the sustainability classroom. Ecological Economics, 64(3): 521-533.

Ignatian Solidarity Network. (n.d.). Laudato si': On care for our common home: Statement of leaders in Catholic higher education globally. Available at https://ignatiansolidarity.net/catholic-higher-ed-encyclical-sign-on/ (accessed May 29, 2018).

IHCD [Institute for Human Centered Design]. (n.d.). Services / inclusive design / news \& events / user/expert lab / New England ADA center / about us. Available at https://humancentereddesign.org/index.php?q=projects/design-social-justice (accessed May 30, 2018).

IPCC [Intergovernmental Panel on Climate Change]. 2014. Climate change 2014: Synthesis report. Contribution of Working Groups I, II and III to the Fifth Assessment Report of the Intergovernmental Panel on Climate Change. Available at http://www.ipcc.ch/report/ar5/syr/.

JAPC [Jesuit Asia Pacific Conference]. 2015. Jesuit universities boost green initiatives. Available at http://www.sjapc.net/2015/09/jesuit-universities-boostgreen-initiatives/ (accessed May 28, 2018). 
Kagan, S., \& Kirchberg, V. (Eds.). 2008. Sustainability: A new frontier for the arts and cultures. Frankfurt am Main: Vas Verlag Fur Akademisch.

Kibert, C. J. 2016. Sustainable construction: Green building design and delivery. Hoboken, NJ: John Wiley \& Sons.

Kolbert, E. 2014. The sixth extinction: An unnatural history. Henry Holt and Company. Lauesen, L. M. 2016. The role of the (governance of the) arts in cultural sustainability: A case study of music. In D. Crowther \& L. M. Lauesen (Eds.), Accountability and social responsibility: International perspectives: 49-74. Emerald Group Publishing.

Mackinnon-Day, P. 2016. An artist's anthropological approach to sustainability. International Journal of Art \& Design Education, 35(3): 307-315.

Macmillan, D. 2011. Lungs. London: Oberon Books.

McKibben, B. 2010. Eaarth: Making a life on a tough new planet. Macmillan.

Medrick, R. 2013. A pedagogy for sustainability education. Journal of Sustainability Education, 5. Available at http://www.jsedimensions.org/wordpress/wp-content/ uploads/2013/06/rickMedrickAPedgagogy-ForExperientialEducationPDFReady.pdf.

Mockler, R. J. 2002. Using the arts to acquire and enhance management skills. Journal of Management Education, 26(5): 574-585. DOI: 10.1177/105256202236727.

Moran, B. 2017. Corporate responsibility: Purpose, culture, and the people strategy. Sustainability: The Journal of Record, 10(4): 232-236. DOI: 10.1089/ sus.2017.0002.

Moser, S. C. 2014. Communicating adaptation to climate change: The art and science of public engagement when climate change comes home. Wiley Interdisciplinary Reviews: Climate Change, 5(3): 337-358.

NEA [National Endowment for the Arts]. 2015. Surprising findings in three new NEA reports on the arts. Available at https://www.arts.gov/news/2015/surprisingfindings-three-new-nea-reports-arts.

Nissley, N. 2010. Arts-based learning at work: Economic downturns, innovation upturns, and the eminent practicality of arts in business. Journal of Business Strategy, 31(4): 8-20. DOI: 10.1108/02756661011055140.

Nulkar, G. 2016. The environmental costs of serving the bottom of the pyramid. Sustainability: The Journal of Record, 9(1): 31-38. DOI: 10.1089/ SUS.2016.29042.

O'Connor, T., \& Gray, J. 2016. Incorporating sustainability across the curriculum. Sustainability: The Journal of Record, 9(1): 21-24.

Ohio State University. 2015. [College of arts and sciences] general education (GE) requirements. Available at https://artsandsciences.osu.edu/academics/currentstudents/advising/ge.

Peil, J., \& van Staveren, I. (Eds.). 2009. Handbook of economics and ethics. Cheltenham, UK / Northampton, MA: Edward Elgar.

Prince Ea. 2015. Dear future generations: Sorry. YouTube. Available at https://www. youtube.com/watch?v=eRLJscAlk1M (accessed May 28, 2018).

Rheinlander, K., \& Kramer, M. 2003. Green curricula? An analysis of environmentally oriented curricula in economics and business administration at German 
institutions of higher education. International Journal of Environment and Sustainable Development, 2(4): 391-411.

Sachs, J. 2015. The age of sustainable development. New York, NY: Columbia University Press.

Scigaj, L. M. 2015. Sustainable poetry: Four American ecopoets. Lexington, KY: University Press of Kentucky.

Second Nature. (n.d.). Second Nature reporting platform. Available at http:// reporting.secondnature.org/ (accessed May 29, 2018).

Shields, D.J., Šolar, S. V., \& Martin, W. E. 2002. The role of values and objectives in communicating indicators of sustainability. Ecological Indicators, 2(1): 149-160. DOI: 10.1016/S1470-160X(02)00042-0.

Silo, N., \& Khudu-Petersen, K. 2016. Hearing ancestral voices through creative art-A tool for environmental education for sustainability. International Journal of Education \& the Arts, 17(9).

Skeirik, K. (n.d.). Incorporating discernment into a music course. Available at https://www.xavier.edu/jesuitresource/online-resources/mission-focusedpedagogy/faculty-work-music.

Skeirik, K. 2014. Music, war and peace. Available at https://skeirikk.wordpress.com/ courses-2/music-war-and-peace/.

Soyka, P. A. 2012. Creating a sustainable organization: Approaches for enhancing corporate value through sustainability. FT Press.

Stefanovic, S. 2018. Miss ex-Yugoslavia: A memoir. Simon \& Schuster.

Sterling, S. 2014. At variance with reality: How to re-think our thinking. The Journal of Sustainability Education, 6. Available at http://www.susted.com/wordpress/ content/at-variance-with-reality-how-to-re-think-our-thinking_2014_06/.

Taylor, S. S., \& Ladkin, D. 2009. Understanding arts-based methods in managerial development. Academy of Management Learning \& Education, 8(1): 55-69. DOI: 10.5465/amle.2009.37012179.

The Ecological City. 2012. American urban and environmental history. Nov. 2. Available at https://ecologicalcity.wordpress.com/green-cincinnati-today/.

Turner, J. M. W. 1844. Rain, steam, and speed-The great Western railway. London: National Gallery.

Wankel, C., \& DeFillippi, R. (Eds.). 2002. Rethinking management education for the 21st century. Information Age Pub.

Ward, K. S. 2013. Creative arts-based pedagogies in early childhood education for sustainability (efs): Challenges and possibilities. Australian Journal of Environmental Education, 29(2): 165-181. DOI: 10.1017/aee.2014.4.

Whelan, T., \& Fink, C. 2016. The comprehensive business case for sustainability. Harvard Business Review, 21(Sustainability): p. 2012.

Willis, G., \& Schubert, W. H. 1991. Reflections from the heart of educational inquiry: Understanding curriculum and teaching through the arts. Albany, NY: SUNY Press.

Wurdinger, S. D., \& Carlson, J. 2010. Teaching for experiential learning: Five approaches that work. Lanham, MD: Rowman \& Littlefield Education. 
Xavier University. (n.d.)a. Economics, sustainability and society (B.A.). Available at https://www.xavier.edu/economics-sustainability-and-society-program/ (accessed May 25, 2018).

Xavier University. (n.d.)b. The plan. Available at https://www.xavier.edu/green/ the-plan (accessed May 29, 2018).

Xavier University Communication Department. (n.d.). Communication BA course sequence. Available at https:/www.xavier.edu/communication-department/ Sample-Course-Sequence.cfm (accessed May 30, 2018).

Yun, D. 2011. Angel's bone. Available at http://channelduyun.com/angels-bone/.

Thanks to Ryan Kambich for research assistance, to students John Means and Daniel Newman, and to Xavier University for Professor Skeirik's faculty research leave.

Nancy Bertaux is Professor of Economics and Sustainability at Xavier University in Cincinnati, Ohio and co-chair of the institution's Sustainability Committee. She is director and founder of the BA in Economics, Sustainability, \& Society and BSBA in Sustainability: Economics \& Management. She has been a Fulbright Senior Scholar in Germany and has taught in Colorado, Ireland, and London. She currently represents Xavier on the Greater Cincinnati Green Business Council (GCGBC).

Kaleel Skeirik is a multi-media composer, music theorist, and Professor of Music at Xavier University in Cincinnati, Ohio. He has composed over 100 works for orchestra, chamber music, choral music, and solo vocalist, premiered new music nationally, and toured as a piano recitalist. Many of his compositions explore issues in social and Earth justice. 